\title{
Determinants of Organizational Commitment A Study of Information Technology Professionals in Pakistan
}

\author{
Sajid Bashir and Mohammad Ismail Ramay \\ Mohammad Ali Jinnah University, Islamabad, Pakistan
}

\begin{abstract}
This study examines the relationship between career opportunities, work life policies, job characteristics and organizational commitment of information technology (IT) professionals in Pakistan. The results show that career opportunities and work life policies in IT professionals are significantly correlated with organizational commitment, while job characteristics do not determine their organizational commitment.

Organizations will have to devise more family friendly policies and provide opportunities for career development to IT professionals to induce organizational commitment. Strategies addressing these issues are also discussed.
\end{abstract}

\section{Introduction}

Effects of organizational commitment on outcomes vary across career stages. This is especially true for the relationship between organizational commitment and turnover (actual and intended) (Cohen, 1991). Procedural justice, information sharing, and worklife policies practices must be considered as complementary means to achieve lower IT turnover rates (Paré \& Tremblay, 2000). Work-family conflict is indeed an issue that can affect almost all aspects of people's lives. People's families, their workplaces and even their own mental and physical health can be affected (Robbins, 2004). IT professionals will willingly remain in organizations where work is stimulating and challenging, chances for advancement are high and if they feel reasonably well paid (Paré \& Tremblay, 2000). Implications suggest a need to move from control-oriented to commitment-oriented work practices and to align configurational HR strategies to these high commitment work practices (Bhatnagar, 2005).

In Pakistan organizations employing IT professionals are seeking strategies which can induce organizational commitment in IT professionals. Several factors affect organizational commitment but present study focuses its relationship with career opportunities, work life policies and job characteristics. No such study about IT professionals is available specific to Pakistan, hence findings will help the organizations to devise strategies which can induce organizational commitment in IT professionals and increase their retention.

\section{Review of literature}

Literature relevant to organizational commitment indicate a number of variables which determine organizational commitment. Some of these findings are given in the following section. 


\section{Career Opportunities}

Career is the interaction of work roles and other life roles over a person's lifespan including both paid and unpaid work in an individual's life. People create career patterns as they make decisions about education, work, family and other life roles (Post, Borgen, Amundson, \&Washburn,2002). A number of researches suggest that the role of employers and employees is changing with reference to career e.g. Ball(1997) argues that as employers take less responsibility, employees need to take control of their own development in order to maintain and enhance their employability. In this changed scenario what is the impact of career opportunities on organizational commitment of employees?. Puah \& Ananthram (2006) suggests, "Career development has a direct influence on the achievement of job satisfaction and career commitment. Highlighting its benefits for the organizations, Hartzenberg (2002) argues, "Organizations are expecting employees to assume greater responsibility for their own future as well as for organization's success. Similarly, Johns (2005) suggests that employees that have advanced would put more effort into their work. The company policies play an important role in providing career opportunities. It seems that the organization may benefit from increasing commitment across all career stages. Increasing commitment in the early career stage is important for decreasing turnover and in the mid- and late-career stages for reducing absenteeism and increasing performance (Cohen, 1991). Effective IT retention strategy will focus on four key categories of HR practices, namely, 1) distributive justice, 2) competence development and career paths; 3) recognition of performance, and 4) empowerment (Paré \& Tremblay, 2000).Shelton (2001) suggests, "Companies cannot develop corporate universities and offer extensive opportunities for internal promotion, they can help people develop career goals and action plans to develop throughout their careers". The career opportunities do affect employee commitment with the organization. Career advancement, autonomy and measurability of output related to commitment indicate that the creation of job ladders and job flexibility will maximize commitment and thus minimize absenteeism and turnover (Johns, 2005). Based on above findings, career opportunities have been identified as a determinant of organizational commitment. Data analysis will determine extent of relationship between organizational commitment and career opportunities among IT professionals in Pakistan.

H1: Career opportunities are positively and significantly related with organizational commitment of IT professionals in Pakistan

\section{Work Life Policies}

Friendly work life policies are required to reduce negative impacts of work life conflict which is defined by Greenhaus and Beutell(1985) as an incompatibility between responsibilities from the work and family. Recently many researchers have attempted to highlight significance of work life policies. Family-friendly policies should cater for the specific 'family' circumstances of all employees (Lilley, 2004). In developed and developing countries, rising proportions of dual earner families, increased female labor force participation and the growing number of aged dependents means that a higher 
proportion of employees have family responsibilities (Hall \& Liddicoat 2005). Researchers also support the idea of flexible timing and working conditions. Organizations need to accommodate these individuals with remote access for telecommuting, childcare centers, referral programs and employee assistance programs (Dockel, 2003). Despite experiencing work-life conflict, employees may maintain relatively high levels of organizational commitment provided that they perceive the procedures used to plan and implement organizational decisions are fair (Siegel et al, 2005). Spending more time at work can be an outcome of employee commitment as Lee \& Hui (1999) argue, "work interference with family may be an indicator of how much devotion one has for work." Some researchers consider organizational policies a source of work life conflicts e.g. Meyer, Stanley, Herscovitch \& Topolnytsky (2002) argue that it is possible that having a sense of being "trapped" in an organization is both stressful for employees and a source of conflict in the home. Lilley (2004) argues that a corporate culture that focuses on 'face time' encourages employees to be on site but does not motivate them towards better performance. It will penalize workers absent from the workplace through the taking of leave or the use of reduced or compressed hours. Reward for 'hard work', often judged by the length of time a worker spends at the workplace, is rejected for recognition of performance outcomes. There is increasingly call for employers to place less emphasis on 'face-time' and focus on work outcome. These findings suggest that the organizational policies are affecting both, the employee performance in the organizations and their organizational commitment. Many researchers favor flexible working hours e.g. Roehling, Roehling \& Moen (2001) suggests "flexible-time benefits are associated with increased loyalty for men and women at all life stages. Dockel (2003), in his study on high technology employees, found that "work life policies have a strong and significant relationship with organizational commitment".

The present study will attempt to find out as to what extent the work life policies are affecting organizational commitment of IT professionals in Pakistan.

H2: Work life Policies are positively related with organizational commitment of IT sector professionals in Pakistan

\section{Job Characteristics}

Job characteristics were defined comprehensively by Hackman \& Oldham (1976) who argued that to enhance employee motivation the job must have five core characteristics i.e. skill variety, task significance, task identity, autonomy and feedback. Reserchers have attempted to examine relationship bewteen job characterestics and different variables including organizational commitment. To raise job satisfaction among their employees, managers need to reduce the gap between the importance and likelihood values for job characteristics that involve the acquisition of skills.(Linz, 2003). There are various dimensions of job characteristics and their importance in the Human Resource Management is well established. All the job characteristics variables had statistically significant correlation with job satisfaction and organizational commitment (Allen, Lambert, Pasupuleti, Tolar \&Ventura, 2004). Autonomy was found to be positively 
related to all three measures of organizational commitment (Johns, 2005). All the retention factors except job characteristics, age and organizational tenure have significant relationship with organizational commitment as a whole (Dockel, 2003). These diverse findings make it interesting to see whether different job characteristics are significantly correlated with organizational commitment of IT professionals in Pakistan or they do not have significant relationship with organizational commitment.

H3: Job Characteristics are positively related with organizational commitment of IT sector professionals in Pakistan

\section{Organizational Commitment}

Organizational commitment has been extensivley researched and different researchers have identified its antecedents and outcomes. Orgnaizational commitment was defined by Allen \& Meyer (1990) as "psychological state that binds the individual to the organization (i.e. makes turnover less likely). This definition will be used in the current study. Relating to commitment with turnover Steers (1977) conducted a comprehensive study developing a model to find out antecedents and outcomes of organizational commitment. Antecedents of organizational commitment are quite diverse in nature and origin (Steers, 1977). Opportunities to leave have a more important effect on turnover than any changes over time in one's commitment to organization (Marsh \& Mannari, 1977). Improvements in commitment levels may have not only positive behavioral consequences, but according to the present results, the indirect outcome of increased employee satisfaction as well (Bateman \& Strasser, 1984). Outcomes of the feelings about work performance (commitment and satisfaction) as well as being in a job and organization that suits one's values and goals (via job-unit influence and work motivation) affect intentions to quit or stay (Stumpf \& Hartman, 1984). Organizational commitment and turnover are both dynamic concepts (Cohen, 1993). Allen \& Meyer (1990) suggested, "commitment is seen as a negative indicator of turnover." Their research also made an important contribution towards defining the three components of organizational commitment. Affective commitment "the employee's emotional attachment to, identification with, and involvement in the organization, Continuance commitment "an awareness of the costs associated with leaving the organization" and Normative commitment "a feeling of obligation to continue employment" (Meyer \& Allen, 1991). However in present study organizational commitment was measured as a whole rather than measuring its three components.

Thus commitment continues to be an important area for research in human resource management and the present study is an attempt to find out its relationship with determinants i.e. career opportunities, work life polices and job characteristics for IT professionals in Pakistan. 
Figure: 1

Relationship between Work Life Policies, Career Opportunities, Job Characteristics and Organizational Commitment

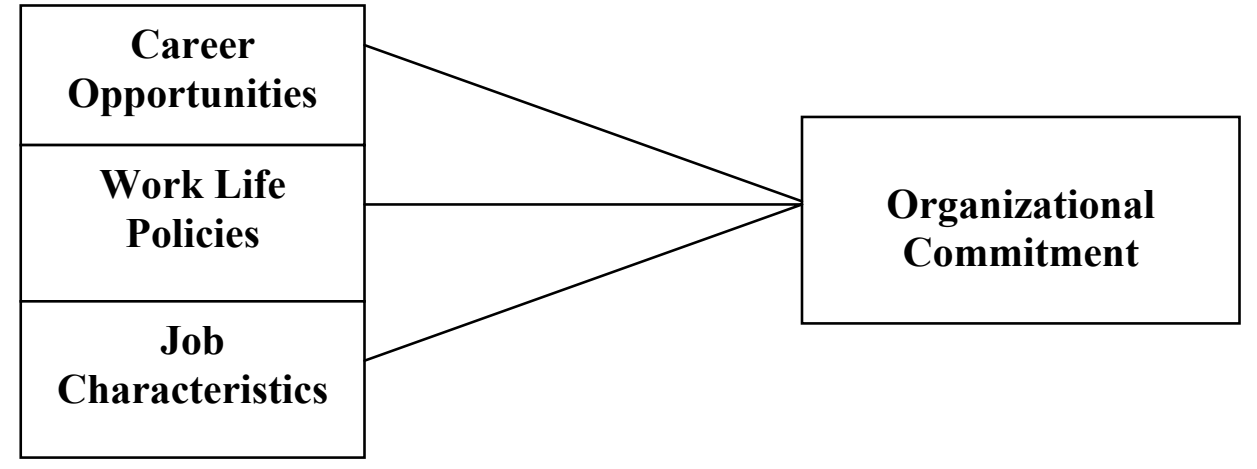

\section{Methodology}

This section discusses the methodology adopted for the research. It includes discussion about questionnaire and participants.

\section{Questionnaire}

The questionnaire was adopted by Dockel (2003) who used it to find out organizational commitment of high technology employees in South Africa. The values for internal consistency and reliability computed by Dockel (2003) are reproduced at table 1 . The questionnaire was adopted with minor modifications as per local requirements of Pakistan. These modifications were in the demographics where the languages of Pakistan were included. Similarly, in the qualification column changes were made as per requirements of Pakistan There was no change for questions relating to organizational commitment, career opportunities, work life policies and job characteristics.

Table 1: Internal Consistency \& Reliability of each scale (Dockel, 2003)

\begin{tabular}{|l|l|c|c|}
\hline \multicolumn{1}{|c|}{ Scale } & \multicolumn{1}{|c|}{ Components } & $\begin{array}{c}\text { Cronbach } \\
\text { Alpha }\end{array}$ & Eigenvalue $^{*}$ \\
\hline \multirow{2}{*}{$\begin{array}{l}\text { Organizational } \\
\text { Commitment }\end{array}$} & Affective Commitment & 0.78 & 4.822 \\
\cline { 2 - 4 } & $\begin{array}{l}\text { Continuance } \\
\text { Commitment }\end{array}$ & 0.61 & 1.386 \\
\cline { 2 - 4 } & $\begin{array}{l}\text { Normative } \\
\text { Commitment }\end{array}$ & 0.76 & 2.015 \\
\hline $\begin{array}{l}\text { Career } \\
\text { opportunities }\end{array}$ & & 0.76 & 2.735 \\
\hline Work Life Policies & & 0.87 & 2.197 \\
\cline { 1 - 1 } Job Characteristics & & 0.41 & 1.350 \\
\hline
\end{tabular}


The response was required on a five point Likert scale (endpoints: $1=$ Strongly disagree, $5=$ Strongly agree). A covering letter explaining the importance of the study was used and the questionnaire were distributed to HR managers of different IT sector organizations including IT departments of different organizations.

\section{Participants}

The participants included IT professionals working in public sector and private sector organizations including banks. Sixteen organizations employing almost 155 IT professionals were selected. Whole population was taken as sample and questionnaires were personally administered. 142 questionnaires were received back thus response rate was $91 \%$. Majority of participants were holding titles of software developers, network administrators and system engineers.

The demographic break down of respondents indicate that majority of respondents were male i.e. $76 \%$. The diversity in organization with reference to gender is increasing in Pakistan and more and more women are joining organizations in different capacities including managerial positions and professional positions like IT professionals but still male professional mangers and workers are quite big in numbers. In present study $76 \%$ respondents were male and majority included young IT professionals having less than 10 years tenure in the organizations. This study is a better indicator of preferences and level of organizational commitment of young IT professionals. The present study focuses high technology IT professionals and thus $80 \%$ respondents possessed Masters or above qualification. The martial status of the respondents is an important demographic in the present study as having a married life and children increase responsibility on individuals and mostly work life conflict situation arises when there is an imbalance between work and family life. The demographics table indicates that $63 \%$ respondents are married and their response presents a true picture of work life conflicts of IT professionals. Pakistan is divided in to four major provinces, Punjab, Sindh, North West Frontier Province (NWFP) and Balochistan. The national language of Pakistan is Urdu and majority of professionals have indicated Urdu as their native language whereas Punjabi is also one of the major language of the respondents. However, demographics indicate that respondents belong to different age groups, and are from different areas of Pakistan. The respondents also include male, female, married and unmarried individuals, thus the sample size is balanced and is representative of IT professionals from various demographical indicators in Pakistan.

\section{Statistical methods}

Statistical tool such as correlation matrix and regression were used for data analysis. Their details are discussed in the following section. 


\section{Correlation Matrix:}

Correlation test was conducted to verify existence of relationship between the independent variables i.e. career opportunities, work life policies, job characteristics and the dependent variable organizational commitment.

\section{Regression Analysis:}

Relative strength of relationships between organizational commitment and its determinants was examined through regression analysis.

\section{Results}

The results obtained by data analysis are discussed in the following section.

Table 2: $\quad$ Correlation Matrix

\begin{tabular}{|l|r|r|r|r|r|r|r|r|}
\hline & Mean & \multicolumn{1}{c|}{ SD } & OC & \multicolumn{1}{c|}{ CO } & WLP & JC & Age & Tenure \\
\hline OC & 3.14 & 0.38 & 1 & & & & & \\
\hline CO & 3.13 & 0.50 & $0.22^{* *}$ & 1 & & & & \\
\hline WLP & 3.04 & 0.78 & $0.26^{* *}$ & 0.10 & 1 & & & \\
\hline JC & 3.11 & 0.49 & 0.15 & 0.12 & 0.12 & 1 & & \\
\hline Age & 28.79 & 4.56 & 0.035 & -0.019 & 0.0001 & -0.168 & 1 & \\
\hline Tenure & 4.86 & 3.8 & 0.009 & 0.003 & -0.080 & -0.185 & 0.944 & 1 \\
\hline
\end{tabular}

${ }^{* *} p \leqslant 0.01, n=142$

$\mathrm{SD}=$ standard Deviation, $\mathrm{OC}=$ Organizational Commitment, $\mathrm{CO}=$ Career opportunities, WLP= Work Life Policies, JC= Job Characteristics

The correlation matrix (Table 2) indicates that Career Opportunities are positively and significantly correlated with Organizational commitment of IT professionals $\left(0.22{ }^{* *}\right)$, $\left.{ }^{* *} . p<.01\right)$ which is supported by Dockel $(2003)$ who found value $\left(0.34\left({ }^{* *}\right),{ }^{* *} . p<.01\right)$. Correlation analysis establishes that Work Life Policies have significant relationship with organizational commitment $\left(0.26\left({ }^{* *}\right),{ }^{* *} . p<.01\right)$. Dockel (2003) also found a significant relationship between Work Life Policies and overall Organizational Commitment $\left(0.31^{* *}\right.$, ${ }^{* *}$. p <.01). Balmforth and Gardener (2006) also found a positive relation ship between work family facilitation (WFF) and organizational commitment. Similarly Siegel et al (2005) found a significant negative relationship between work life conflict and organizational commitment. There is no significant relationship between job characteristics and organizational commitment $(0.15)$. These findings are supported by Dockel (2003) who found no significant relationship between job characteristics and 
overall organizational commitment. These findings are also partially supported by Allen et al (2004). However the findings are contrary to findings of Steers (1977). Age and tenure were also included in the correlation analysis but both have shown a very weak and insignificant relation ship with organizational commitment.

Table 3: $\quad$ Regression Analysis

\begin{tabular}{|l|c|c|c|}
\hline \multicolumn{1}{|c|}{$\begin{array}{c}\text { Independent } \\
\text { Variable }\end{array}$} & Beta & t-value & P-value \\
\hline Constant & 2.102 & 7.697 & 0.000 \\
\hline Career Opportunities & 0.141 & 2.285 & 0.024 \\
\hline Work Life Policies & 0.113 & 2.837 & 0.005 \\
\hline Job Characteristics & 0.080 & 1.270 & 0.206 \\
\hline
\end{tabular}

$\mathrm{n}=142 ; \mathrm{R}$ Square $=0.116 ; \quad$ Adjusted $\mathrm{R}$ Square $=0.097 ;$

$F=6.044 \quad$ Significance $F=.0006$;

Dependent Variable $=$ Organizational Commitment

Table 3 presents the regression coefficient of independent variables on dependent variable i.e. organizational commitment. The regression analysis accounted for $9 \%$ variance in the organizational commitment. Out of these three independent variables, Career opportunities and Work life policies had a significant effect on organizational commitment while job characteristics had no significant effect on organizational commitment.

\section{Discussion}

The purpose of current study was to examine relationship between career opportunities, work life policies, job characteristics and organizational commitment among IT professionals in Pakistan. As per hypothesis, career opportunities emerged as a determinant of organizational commitment. Being key components of human resource development, professionals of any discipline are more concerned about career opportunities which allow them to grow in organizational hierarchy and professionally both. Respondents' answers to various questions showed that they feel their chances of getting promoted are good and they have good career opportunities. The possible reason for this response can be that the respondents are amongst the category of professionals who are in much demand in Pakistan. To retain them organizations are trying to provide better career opportunities otherwise the competitors can easily attract these professionals.

The work life of IT professionals in Pakistan varies depending on nature of the organization where they are working. The public sector organizations in Pakistan follow a typical bureaucratic structure. The employees are supposed to work for about 39 hours per week but actual time spent is less than this standard. Thus IT professionals 
employed in public sector organizations work in a relatively relaxed environment. However in private sector organizations the situation is quite different. A typical work week extends from 40-48 but employees including the IT professionals are supposed to work beyond this limit. Frequent late sittings in the office create work life conflict for these employees. The results of present study indicate that work life policies determine organizational commitment. An explanation to this relationship is that IT professionals feel that their role as spouse is affected due to work life conflicts. Hence friendly work life polices can induce organizational commitment in IT professionals. Organizations can use different time based strategies like flex time to reduce the work life conflicts of these employees.

However contrary to research hypothesis job characteristics do not determine organizational commitment of IT professionals in Pakistan. The possible explanation to this can be that in Pakistan majority of organizations follow a centralized authority structure. Jobs are designed with least autonomy, significance and feed back. Similarly use of personal initiative and autonomy at jobs is also discouraged in most of Pakistani organizations. Employees who follow organizationally designed job patterns are appreciated and rewarded while innovation and creativity is generally discouraged. Hence employees and professionals in Pakistani organizations prefer jobs with high formalization. Response by most of IT professionals to questionnaires also supports this argument.

\section{Implications}

The present study provided a number of implications for organizations employing IT professionals in Pakistan. The career opportunities for IT professionals in Pakistan have got two dimensions. Firstly the IT professionals must take initiative to identify their career development needs and accordingly seek support by the management to facilitate attainment of these objectives. Unless the IT professionals themselves take the responsibility for their career development, the management will be least interested in this important area. The second dimension is relevant to the management in the organizations employing IT professionals. They can assist these professionals by providing them an opportunity to grow within the organization. More involvement by the managers is required regarding development of career plans of IT professionals. This can reduce the high turnover rate of IT professionals in Pakistan. Being highly paid professionals their lower order needs are not dominant and that they are more concerned about their growth needs. They will prefer to work in organizations which provide them an opportunity to grow in organizational hierarchy and professionally both.

For work life policies because of their demanding jobs IT professionals have to sacrifice their family time which is a potential cause of work life conflict. Organizations need to identify major causes for this conflict and introduce more balanced work life policies to increase organizational commitment. Although IT professionals rank work as their main priority, still their family issues must be looked after by the organizations by providing more friendly work life policies. In Pakistan the managers generally evaluate their subordinates on the basis of time they spend in the organization rather than their actual 
output. Thus employees fear that if they use flexible work arrangements they will be seen less favorably for promotions or reward distribution. This evaluation needs a change especially for IT professionals and their actual out put rather than the time they spend in the organizations, should be the basis for evaluation. The managers need to embed a new culture in Pakistani organizations with flexible policies that even if IT professionals are sitting at home and giving the desired output through telecommuting, this must be seen positively rather than treating it inefficiency. In Pakistan the female partner has to fulfill the entire household responsibilities regardless of the time she spends in office and mostly it is not possible for her to reach office early. Hence flextime can motivate these professionals to continue their jobs and contribute toward organizational success. Similarly a number of IT students who are capable of doing part time work do not find any opportunity in the organizations to work. If organizations can introduce the concept of job sharing they can find a number of competent professionals with innovative ideas working for their organizations.

Job characteristics are the area which has received the least attention to induce organizational commitment in IT professionals of Pakistan. The jobs are organizationally designed which do not take into account the individual differences. As a result the IT professionals do not consider job characteristics important. The role of the management in this area is simplified as majority of IT professionals are more concerned with growth needs and that they are looking for challenge from work itself. Thus management's role in designing the job is of a facilitator rather than a guide.

The overall findings of the study are quite helpful in finding out determinants that can induce organizational commitment in IT professionals of Pakistan. However the regression analysis indicates that only $9 \%$ of organizational commitment in IT professional is explained by variables tested in present study. As per argument of Lok, Westwood \& Crawford (2005) commitment continues to be a variable of significant theoretic and pragmatic interest and it is important that a more fine-grained understanding of its determinants be developed. Hence it would be interesting to find out, through further research the determinants which also affect organizational commitment of IT professionals in Pakistan.

\section{References}

Allen, R.I., Lambert, E.G., Pasupuleti, S., Tolar, T.C. \& Ventura, L.A. (2004). The impact of job characteristics on social and human service workers. Social work and society, 2(2), 173-188.

Allen, N.J., \& Meyer, J.P. (1990). The measurement and antecedents of affective, continuance and normative commitment to the organization. Journal of Occupational Psychology, 63, 1-18.

Ball, B. (1997). Career management competences - the individual perspective. Career Development International, 2(2), 74-79. 
Balmforth, K., \& Gardner.D. (2006). Conflict and facilitation between work and family: Realizing the outcomes for organizations. New Zealand Journal of Psychology, 35, 69-76.

Bateman, T.S., \& Strasser, S. (1984). A longitudinal analysis of the antecedents of organizational commitment. Academy of Management Journal, 27, 95-112.

Bhatnagar, J. (2005). The power of psychological empowerment as an antecedent to organizational commitment in indian managers. Human Resource Development International, 8, $419-433$.

Cohen, A. (1991). Career stage as a moderator of the relationships between organizational commitment and its outcomes: A meta-analysis. Journal of Occupational Psychology, 64, 253-268.

Cohen, A. (1993). Organizational commitment and turnover: a Meta analysis. Academy of Management Journal, 36, 1140-1157.

Dockel, A. (2003). The effect of Retention factors on organizational commitment: An investigation of High Technology Employees. Unpublished doctoral dissertation, University of Pretoria, South Africa.

Greenhaus, J.H.,\& Beutell,N.J. (1985). Sources of conflict between work and family Roles. Academy of Management Review, 10, 76-88.

Hackman, J. R., \& Oldham, G. R.(1976). Motivation through the design of work: Test of a theory. Organizational Behavior and Human Performance, 16, 250-279.

Hall, L., \& Liddicoat, L. (2005). Challenges to developing effective family friendly work practices: findings from New Zealand. Research and Practice in Human Resource Management, 13(1), 1-17.

Hartzenberg, J.S. (2002). The implementation of career management practices in the South African public service. Unpublished doctoral dissertation, University of Pretoria, South Africa.

Johns, R. (2005). Determinants of organizational commitment among U.S. workers. Unpublished master's thesis, Duquesne University.

Lee, C., \& Hui, C. (1999). Antecedents and outcomes of work-family interface. Research and Practice in Human Resource Management, 7(1), 35-51.

Lilley, S. (2004). Whose role is it anyway? Implementing family-friendly workplace practices in New Zealand. University of Canterbury, Social Science Research Centre research project. 
Linz, S.J. (2003). Job satisfaction among Russian workers. Unpublished manuscript, University of Michigan.

Lok, P., Westwood, R., \& Crawford, J. (2005). Perceptions of organizational subculture and their significance for organizational commitment. Applied Psychology: An International Review, 54, 490-514.

Marsh, R.M., \& Mannari, H. (1977). Organizational commitment and turnover: A prediction study. Administrative Science Quarterly, 22, 57-75.

Meyer, J.P., \& Allen, N.J. (1991). A three component conceptualization of organizational commitment. Human Resources Management Review, 1(1), 61-89.

Meyer, J.P., Stanley, D., Hescovitch, L., \& Toplnytsky, L. (2002). Affective, continuance and normative commitment to the organization: A meta-analysis of antecedents, correlates and consequences. Journal of Vocational Behavior, 61, 20-52.

Paré, G., \& Tremblay, M. (2000). The measurement and antecedents of turnover intentions among IT professionals. Scientific Series, 33, 1-34.

A practical manual for developing, implementing and assessing career counseling services in higher education settings (2002). Paris: UNESCO (Need a document number here for retrieval purposes), Post, A., Borgen. W., Amundson,N., \& Washburn. C.

Puah, P. \& Ananthram, S. (2006). Exploring the antecedents and outcomes of career development initiatives: Empirical evidence from Singaporean employees. Research and Practice in Human Resource Management, 14, 112-142.

Robbins, A. (2004). Work family conflict. Unpublished senior honors thesis.

Roehling, P.V., Roehling, M.V., \& Moen, P. (2001). The relationship between work-life policies and practices and employee loyalty: A life course perspective. Journal of Family and Economic Issues, 22, 141-170.

Shelton, K. (2001). The effects of employee development programs on job satisfaction and employee retention. Unpublished master's thesis, University of WisconsinStout.

Siegel, P.A., Post, C., Brockner, J., Fishman, A.Y., \& Garden, C. (2005). The Moderating influence of procedural fairness on the relationship between work-life conflict and organizational commitment. Journal of Applied Psychology, 90, 1324.

Steers, R.M. (1977). Antecedents and outcomes of organizational commitment. Administrative Science Quarterly, 22, 46-56. 
Stumpf,S.A., \& Hartman, K. (1984). Individual exploration to organizational commitment or withdrawal. Academy of Management Journal, 27, 308-329. 